\title{
ERRATUM
}

Mirian R. L. Moura · Gilberto de Nucci · Susanne Rath

Felix G. R. Reyes

\section{LC-APCI-MS-MS methodology for determination of glybenclamide in human plasma}

Published online: 16 April 2004

(C) Springer-Verlag 2004

\section{Anal Bioanal Chem (2004) 378:499-503}

Due to a technical error Fig. 2 was reproduced incompletely. The complete figure is printed below:

The online version of the original article can be found at http://dx.doi.org/10.1007/s00216-003-2248-8

M. R. L. Moura · F. G. R. Reyes (®)

Department of Food Science, State University of Campinas,

P.O. Box 6121, CEP 13.083-970 Campinas, SP, Brazil

e-mail: reyesfgr@fea.unicamp.br

G. de Nucci

Department of Pharmacology, State University of Campinas,

P.O. Box 6111, CEP 13.084-971 Campinas, SP, Brazil

S. Rath

Department of Analytical Chemistry, State University of Campinas, P.O. Box 6154, CEP 13.084-971 Campinas, SP, Brazil 

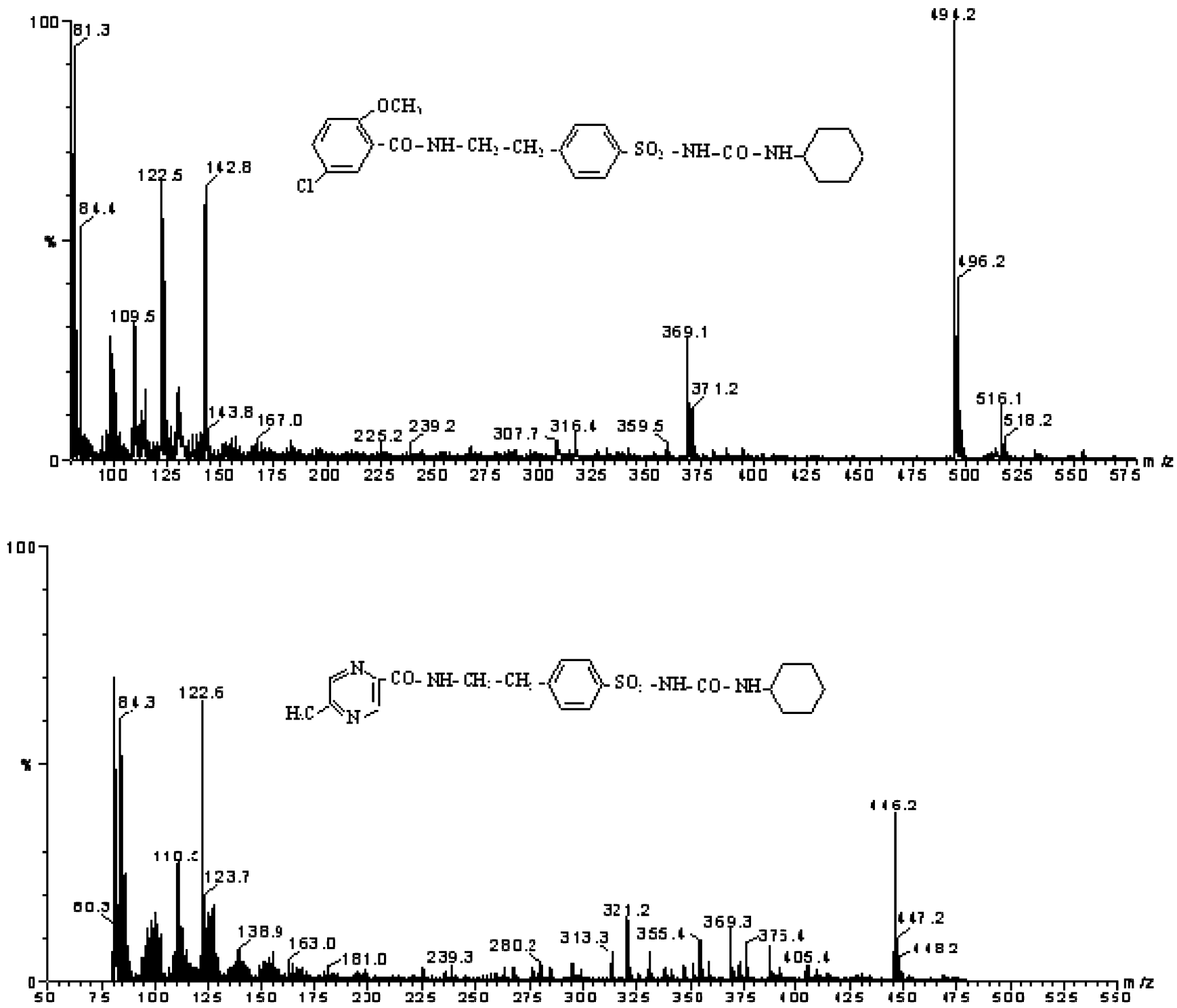

Fig. 2 Product ion mass spectrum of glybenclamide and protonated glypizide 